\title{
Evolution of Infant Mortality in Ecuador: A Spatial Analysis From 2010 to 2019
}

Karina Lalangui Vivanco ( $\nabla$ lalanguik@gmail.com )

Instituto Nacional de Investigación en Salud Pública

Karina Rivadeneira Maya

Ministerio de Salud Pública

Christian Sánchez-Carrillo

Universidad Autónoma del Estado de México

Gersain Sosa Cortéz

Universidad Autónoma del Estado de México

Emmanuelle Quentin

Universidad UTE

\section{Research Article}

Keywords: Infant mortality, Ecuador, spatio-temporal analysis, LISA, Mann-Kendall.

Posted Date: August 25th, 2021

DOl: https://doi.org/10.21203/rs.3.rs-821151/v1

License: (c) (1) This work is licensed under a Creative Commons Attribution 4.0 International License.

Read Full License 
3 Karina Lalangui Vivanco ${ }^{1}$, Karina Rivadeneira Maya ${ }^{2}$, Christian Sánchez-Carrillo ${ }^{3}$, Gersain Sosa

4 Cortéz $^{3}$, Emmanuelle Quentin ${ }^{4}$

$5{ }^{1}$ Instituto Nacional de Investigación en Salud Pública, Centro de Investigación EpiSIG, Quito, Ecuador

$6 \quad{ }^{2}$ Ministerio de Salud Pública, Quito, Ecuador

$7 \quad{ }^{3}$ Universidad Autónoma del Estado de México, Facultad de Geografía, Toluca, México

$8{ }^{4}$ Universidad UTE, Centro de Investigación en Salud Pública y Epidemiología Clínica, Quito, Ecuador

9 Correspondence: Karina Lalangui, lalanguik@gmail.com, https://orcid.org/0000-0001-8506-4107

10 Karina Rivadeneira Maya, kryvadeneira@hotmail.com, https://orcid.org/0000-0003-3371-0386

11 Christian Sánchez-Carrillo, sanchezcci27@gmail.com, https://orcid.org/0000-0003-0498-9269

12 Gersain Sosa Cortéz, gersaingeo@gmail.com , https://orcid.org/0000-0002-0162-235X

13 Emmanuelle Quentin, emmanuelle.quentin@gmail.com, https://orcid.org/0000-0001-5600-2361

\section{Abstract}

16 The health situation of children is fundamental for the big picture of public health in a country.

17 Particularly, the death of children under one year of age, calculated through the infant 18 mortality rate is still a key indicator, especially in Latin America where the overall rate has 19 been constantly decreasing down to 13.9 infant deaths per 1000 live births. But this global 20 figure encompasses geographical and temporal disparities within the same country. This is 21 why it is interesting to analyze this evolution through a geomatic method of spatial 22 prioritization. By combining hotspots detection (Local Indicators of Spatial Association, LISA)

23 and time trend over 20 years (Mann-Kendall) at municipal level data from Ecuador, a country 24 with infant mortality similar to the regional average, we obtain the most critical townships that 25 should receive special attention with respect to maternal and infant health.

\section{Keywords}

28 Infant mortality, Ecuador, spatio-temporal analysis, LISA, Mann-Kendall. 
31 All around the world, statistic measures of mortality are used to evaluate the health state of a

32 population [1] and consequently reflect the socio-economic development, general conditions

33 of life and social wellbeing of a country [2]. Among these measures, the infant mortality rate

34 (IMR) is one of the indicator most used in health [3] and is defined as the likelihood of a live

35 birth to die before the age of one [4].

36 In Latin America and the Caribbean, progress in child survival has been remarkable, starting

37 with the United Nations (UN) Millennium Development Goals (MDGs). Between 1990 and

382015 , the mortality rate of children under five, including those under one year of age, has been

39 reduced by $67 \%$ [5]. However, there is evidence that the mortality rate affects populations with

40 lower socioeconomic levels more strongly $[6,7]$. According to information obtained from the

41 National Institute of Statistics and Censuses (INEC) [8], Ecuador's IMR has decreased by

$4212.7 \%$ for every 1000 births between 1990 (21.8\%) and 2016 (9.1\%). According to Pan

43 American Health Organization / World Health Organization (PAHO/WHO) [9], in 2017 Ecuador

44 recorded an IMR of 8.9 per 1000 children born, below Bolivia (50.2\%o), Colombia (17.2\%o),

45 Brazil (15.1\%), Peru (15\%o), Venezuela (14.7\%o), Paraguay (14.7\%o) and Argentina (9.7\%o).

46 There are studies that have focused on understanding infant mortality from a spatial [10] and

47 temporal [11] or both [12] point of view. With the advance of technology in geographic 48 information systems (GIS), spatial analysis methods have begun to be used for 49 epidemiological and health research [13], which can contribute to policy intervention at the 50 geographic area level [10]. For example, some studies suggest that mortality varies according 51 to geographical region, and show spatial patterns with strong regional differences where high-

52 risk areas can be identified for policy planning and efficient resource allocation (demographic, 53 socio-economic) $[14,15]$.

54 This study proposes an analysis of the spatial and temporal variations of infant mortality (IM) 55 in Ecuador at the municipality level and seeks out those areas where there are significant 56 groupings below or above the national average. This could help to prioritize sectors where 57 greater accessibility and availability of child health care services are needed. In order to 
58 prioritize areas of action, it is of interest to identify the municipalities in which the highest rates

59 are found and in which the trend is strongly increasing.

60 No studies have been found in Ecuador where spatial analysis is used for infant mortality,

61 however our analysis is congruent with other research in Ecuador on suicide, cancer, and

62 neglected tropical diseases that have used significant spatial clusters to determine critical

63 areas $[16,17,18]$. The methods used in this analysis have also been applied in other

64 countries to determine spatial variation, spatial clusters and risk factors influencing infant

65 mortality $[10,19]$.

66

\section{Methods}

\section{Study area and infant mortality rate}

69 Ecuador is located in South America, bordering Colombia (north), Peru (south-east) and the

70 Pacific Ocean (west). Politically, it is divided into 24 provinces (Figure 3. A) and 221 counties

71 that correspond to municipalities or communes (second political-administrative level after

72 provinces). It has four natural regions: coast, highlands, Amazon and Galapagos Islands. For

73 this study only continental Ecuador was considered.

74 The public databases of live births and general deaths are downloaded from the INEC website

75 from 2010 to 2019 [8]. The data on deaths of children under one year of age in the study area

76 together with the data on live births are totalized by spatial unit. These data are used to

77 calculate the infant mortality rate per 1000 live births during a year and to construct thematic 78 maps.

\section{Time trend}

80 The Mann-Kendall non-parametric statistical test is used to determine the time trend over a 81 period of the annualized IMR. To apply this test, the data do not need to fit any particular 82 distribution [20]. The statistic makes combinations of each pair of observed values, over time,

83 that is, it checks whether $I M R_{j}>I M R_{i}$ or $I M R_{j}<I M R_{i}$ and counts the number of pairs that 84 increase or decrease over time (it is the relative frequency of increases minus the relative 85 frequency of decreases), it is calculated for each spatial unit as [21]: 


$$
S=\frac{2(t-2) !}{t !} \sum_{i=1}^{t-1} \sum_{j=i+1}^{t} \operatorname{sign}\left(I M R_{j}-I M R_{i}\right)
$$

where the sign function is given by

$$
\operatorname{sign}\left(I M R_{j}-I M R_{i}\right)=\left\{\begin{array}{l}
1 \text { if }\left(I M R_{j}-I M R_{i}\right)>0 \\
0 \text { if }\left(I M R_{j}-I M R_{i}\right)=0 \\
-1 \text { if }\left(X_{j}-X_{i}\right)<0
\end{array}\right\}
$$

87 IMRi is the IMR in year $i \in\{1,2, \ldots, t-1\}$ with $t$ as the number of available years and IMRj is

88 the IMR in year $j=(i+1) \in\{1,2, \ldots, t\}$.

89 Mann-Kendall values range from -1 to +1 . When a value approaches +1 it means there is a

90 monotonic upward trend, when it approaches -1 , the trend is downward and a value of 0

91 indicates no trend.

\section{Spatial trend}

93 The observed variable, in this case the IMR in the study area is represented with maps and

94 using the spatial statistics technique for cluster detection using the Moran Indicator both

95 globally and locally. The aim is to observe the spatial dependence that may or may not exist

96 between nearby locations.

97 Considering a set of $N$ spatial units in a region, the spatial autocorrelation represents the 98 relationship between the IMR, in one spatial unit, and the IMR values of its n neighbors, which 99 can be visualized through a connectivity map. To quantify the closeness between two spatial 100 units, a positive $n \times n$ matrix $W$ is used, made up of $n(n-1)$ spatial weights called wi,j which are 101 defined based on binary contiguity, like this:

$$
w_{i, j}=\left\{\begin{array}{l}
w_{i, j}=1 \text { if } j \neq i, \text { neighbouring space units } \\
w_{i, j}=0 \text { opposite case }
\end{array}\right\}
$$

102 The Moran Index (I) is the test considered to be the most applied and statistically strongest to 103 detect spatial independence from debris, this being a summary measure of the intensity of the 104 spatial association between units [22, 23]. Its range of values is based on the weight matrix, 105 usually varying between -1 and +1 but not necessarily restricted by this, unlike a correlation 106 coefficient. If its neighboring municipalities tend to have similar values in their IMR, I will be 
107 positive indicating that the pattern is clustered, if they are different, I will be negative, that is,

108 the pattern is regular and when spatial randomness is present the expected value of $I$ is given 109 by $E[I]=(-1) /(n-1)$, as $n$ increases, $E[I]$ approaches 0 [24]. It is similar by Waller as a spatial 110 extension of the Pearson correlation coefficient.

111 Given $i$ and $j$ in $\{1,2, \ldots, n\}$, the index is defined by:

$112 \quad I=\frac{n}{\sum_{i=1}^{n} \sum_{j=1}^{n} w_{i, j}} \frac{\sum_{i=1}^{n} \sum_{j=1}^{n} w_{i, j}\left(x_{i}-\bar{X}\right)\left(x_{j}-\bar{X}\right)}{\sum_{i=1}^{n}\left(x_{i}-\bar{X}\right)^{2}}$ for $j \neq i$,

113 where $n$ is the total of municipalities, $x_{i}$ the IMR in municipality $i, x_{j}$ the IMR in another

114 municipality $j, \bar{X}$ the average of the IMR and $w_{i, j}$ the elements of the contiguity matrix $W$ that 115 links municipality $i$ to $j$.

116 As there are spatial effects such as heterogeneity that refer to the indistinct behavior of the 117 variable observed in each of the units, local patterns can be detected that with the global 118 measure were ignored, so local measures are introduced as Local Spatial Association 119 Indicators (LISA) is calculated as [25]:

$$
I_{i}=\left(x_{i}-\bar{X}\right) \sum_{j=1}^{n} w_{i, j}\left(x_{j}-\bar{X}\right) \text { for } j \neq i
$$

120 With this analysis, using the calculation of Moran's $I_{i}$ and the scatter plot, four categories of 121 groupings can be identified by the type of spatial association: the hotspots, which are 122 municipalities with an above-average rate and the rate of their neighbors as well, the high-high 123 category, or otherwise the below-average rate, the low-low category, and the outliers (or 124 outliers), which are municipalities with an above-average rate but the rates of their neighbors 125 are below the average, the high-low category, or otherwise the low-high category. To see if 126 these groupings were not created randomly, a hypothesis test is done, a significance test that 127 uses a permutation test.

\section{Prioritization criteria for identification of spatial-temporal critical areas}

129 Different types of criteria can be developed and implemented according to the prioritization 130 needs of the study. 
131 In this case, the methodology was designed according to logical criteria. First, in order to 132 eliminate inconsistent rates, municipalities with less than 2 deaths were excluded. The

133 counties with higher IMR during the most recent year were selected, using the $90 \%$ percentile

134 threshold. The frequency, in number of year, of pertaining to a high-high or hotspot cluster is 135 used to give priority. The third factor considered is the higher positive trend over all the period 136 studied.

137 Eventually the hotspot repetition over years can be more strictly evaluated using the logical 138 AND operator instead of the OR operator (Figure 1).

139 Figure 1. Methodology in 3 steps.

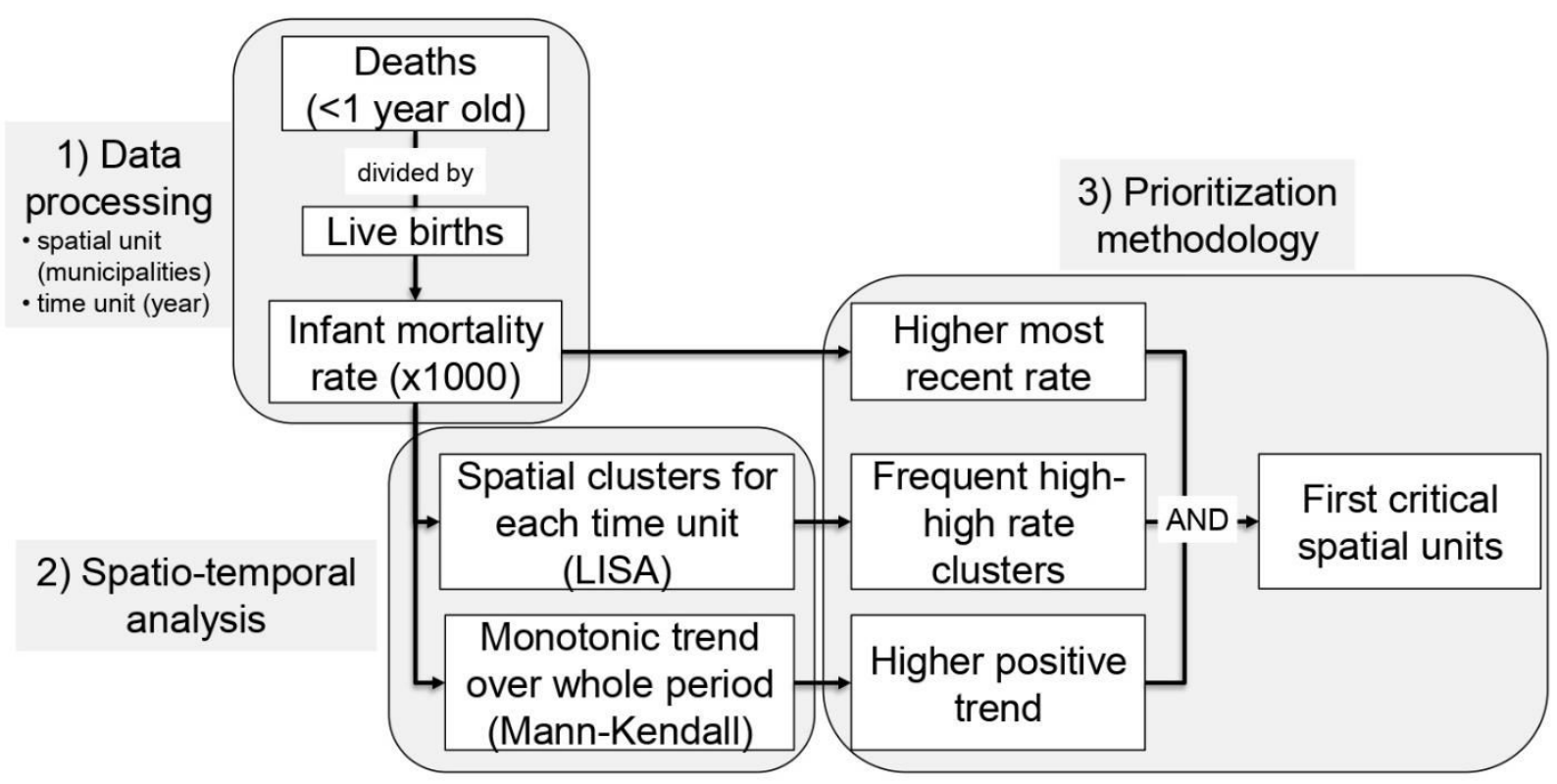

\section{$141 \quad$ Results}

142 Since 2000 , the national IMR has been steadily decreasing, but as of 2014 , the rate has

143 begun to grow again which is of great concern (Figure 2).

144 Figure 2. Yearly evolution of the national infant mortality rate (2000-2019). 


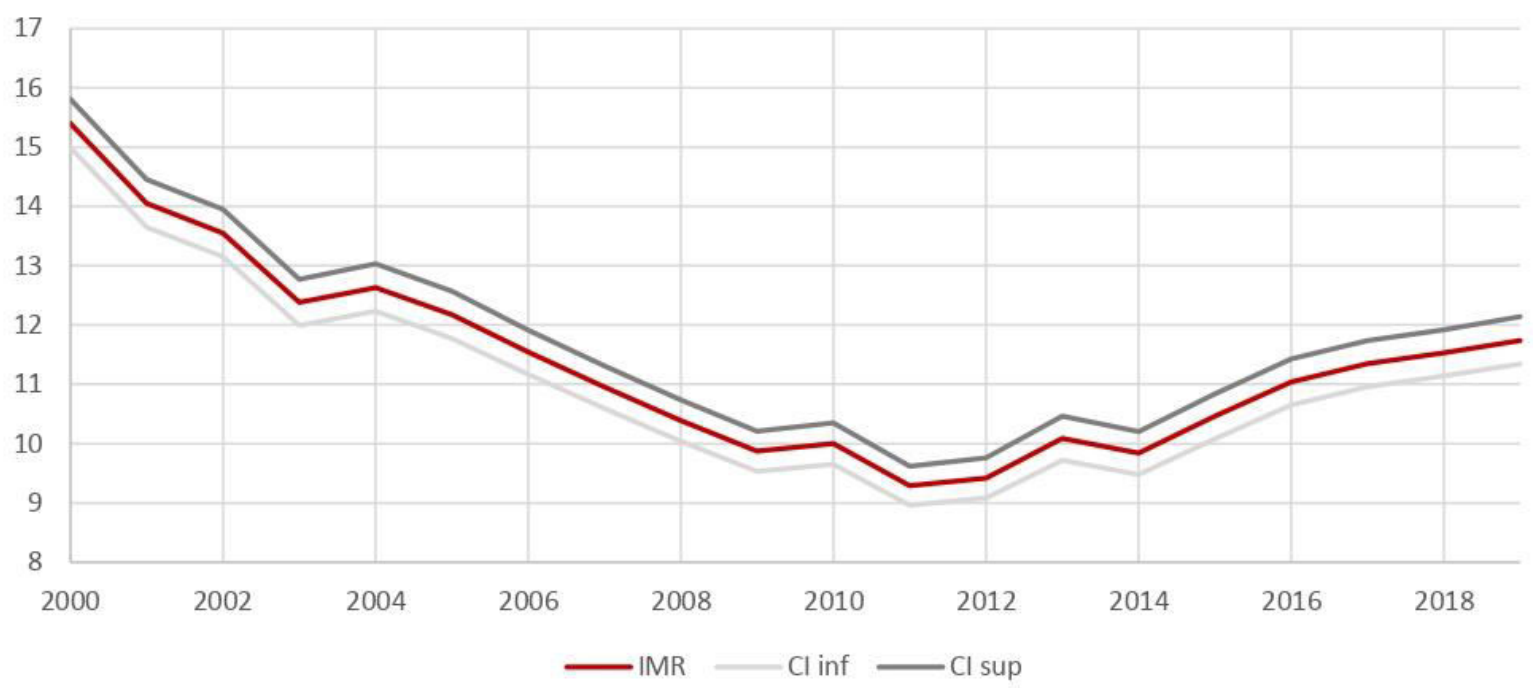

146 Regarding the leading cause of deaths in children under one year of age in 2019, of the 3355

147 children who died $15 \%$ (504) died from respiratory difficulties, $7.7 \%$ (257) from bacterial 148 sepsis, $5.2 \%$ (175) from pneumonia and $4.1 \%$ (137) from other congenital heart 149 malformations. The following chart shows the top ten causes of mortality in children under one 150 year of age for 2019 (Figure 3).

151 Figure 3. Top ten causes of death in children under one year of age in 2019.

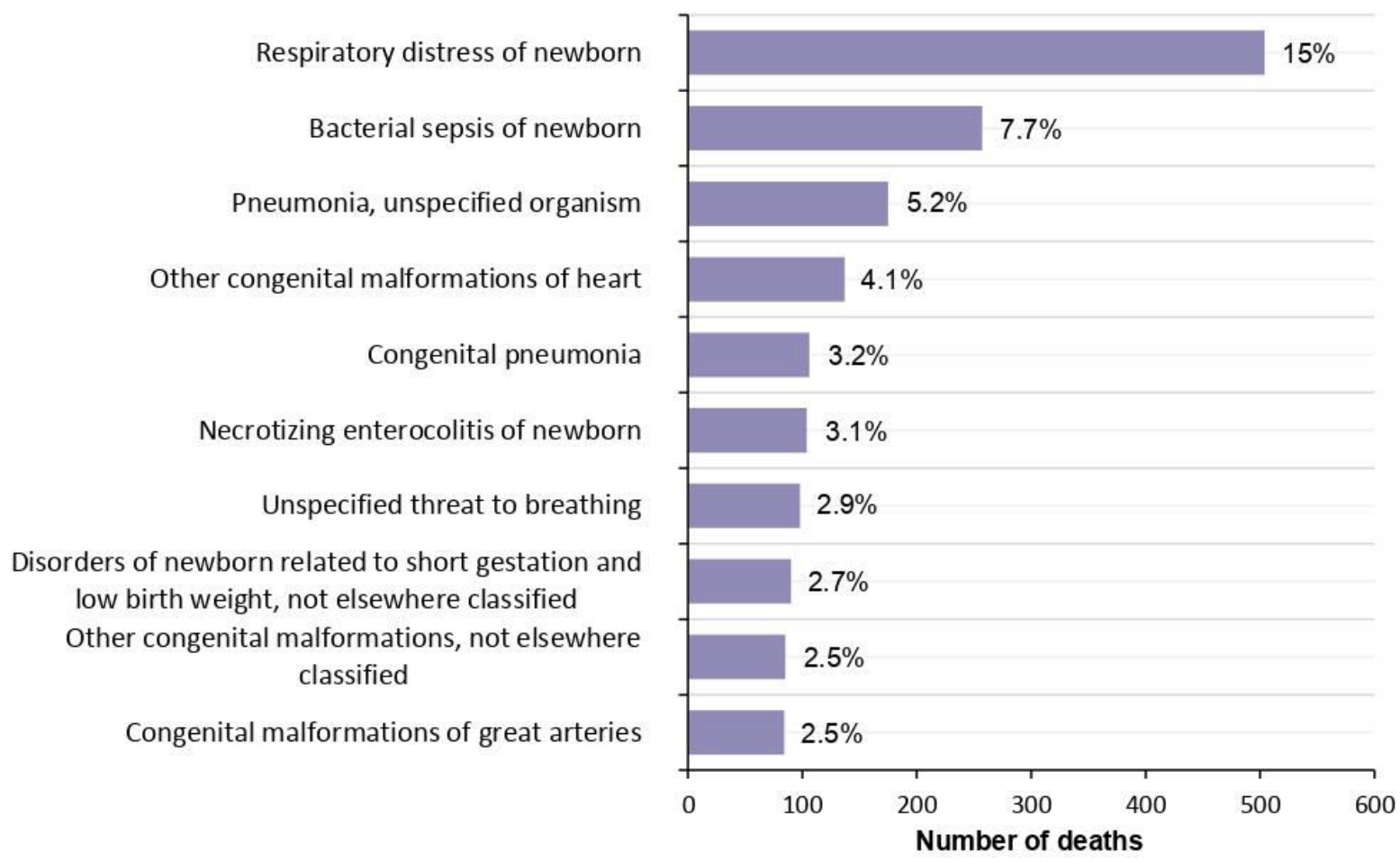

153 Figures 4 and 5 show the spatial distribution of the incidence rates of mortality in children

154 under one year of age and the temporal trends analyzed by the Mann-Kendall method (the 
155 number in brackets indicates how many municipalities are in the category) in the 221 156 municipalities of continental Ecuador. The trends show that the rates are not spatially 157 constant. At the regional level, there is a slow increase in IMR rates, mainly in the highlands 158 and the Amazon. In the highlands, the municipalities with rates above $>16.7 \%$ are Ibarra, 159 Cuenca, with high growth trends, and Guaranda and Tulcan with medium growth trends, and 160 Latacunga and Quito with low growth trends. Similarly, the municipality of Guamote has a rate 161 above the threshold, however, this trend is steadily decreasing over time.

162 Of the 41 municipalities in the Amazon, 15 maintain an increasing trend between medium and 163 low, however, the municipality Morona, Lago Agrio and Quijos are the only ones rates above 164 the threshold.

165 A particular case on the coast is the Piñas municipality, where the rate increased from $0 \%$ in 1662010 to 157.77 deaths per 1000 live births in 2019 , making it the municipality with the highest 167 increasing trend in the entire country. Another important aspect to highlight within this region is 168 that the municipalities of Manta and Guayaquil, being provincial capitals, have rates above the 169 established threshold and with an average upward trend. San Lorenzo in the coastal 170 Esmeraldas province is the only municipality that presents a high decreasing trend.

171 Figure 4. Provinces of Ecuador (Panel A). Infant mortality rate for 2010 to 2019 (Panel B-K). 


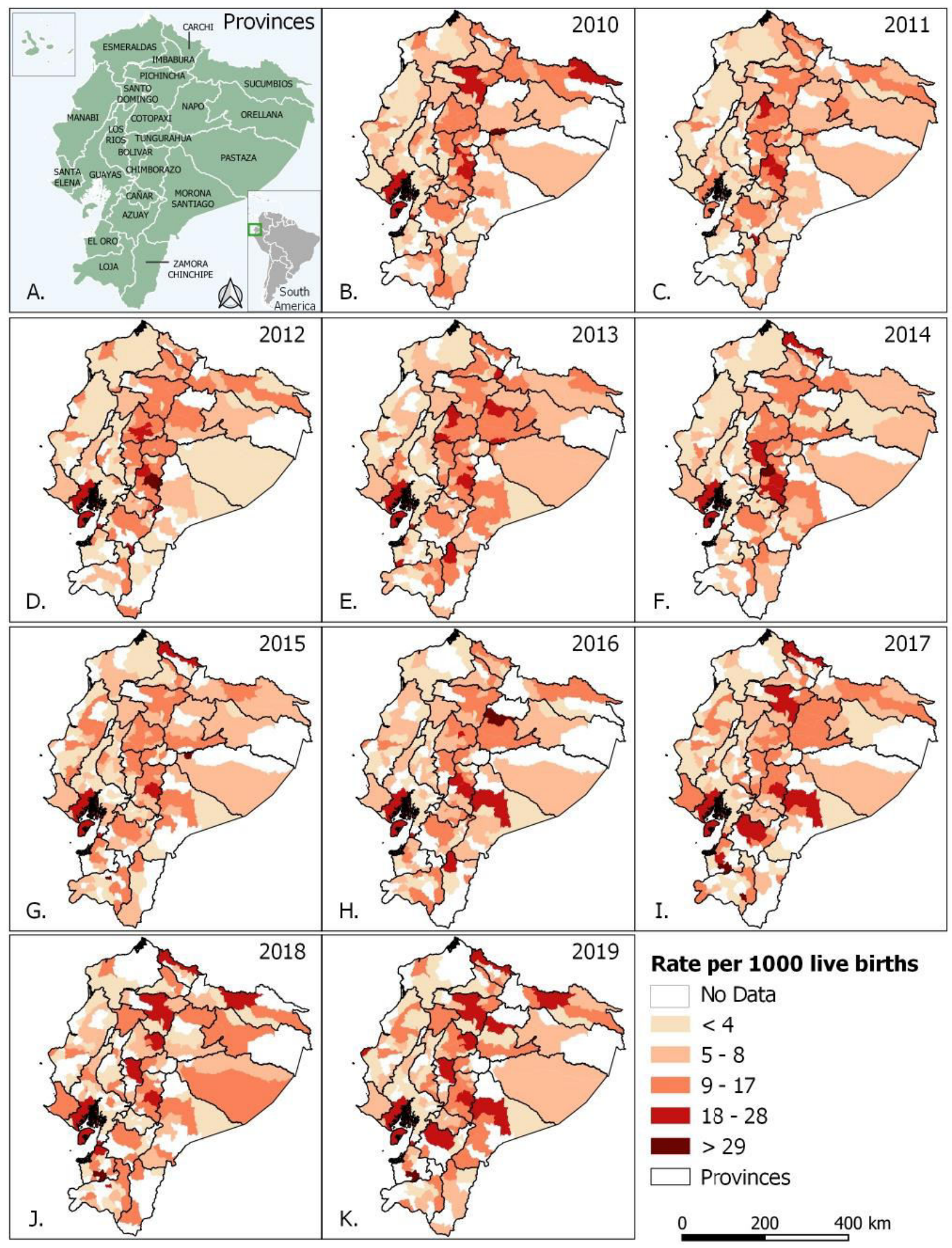

173 Figure 5. Time trend map of Mann-Kendall (Tau) for the period 2010 to 2019. 


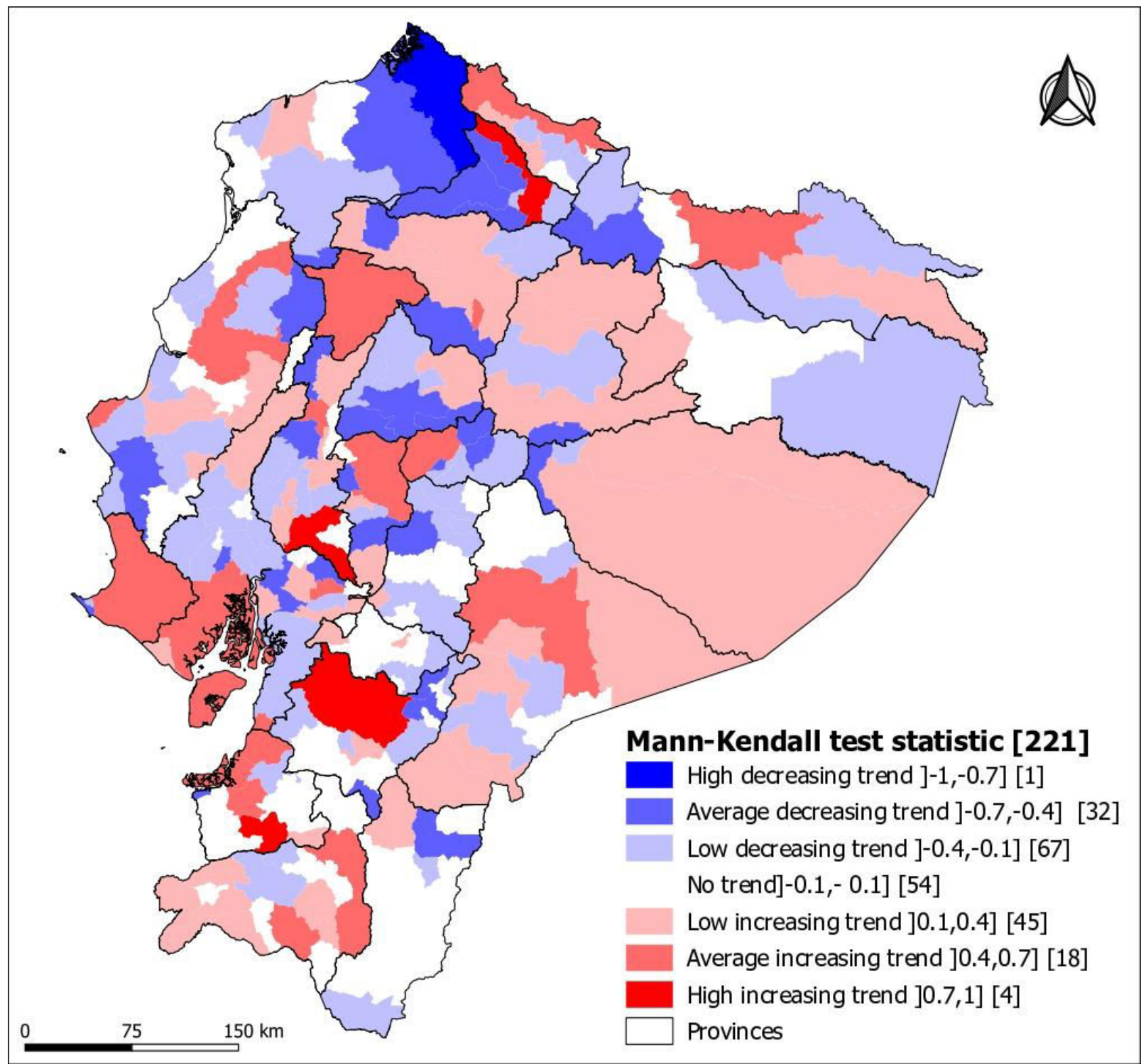

175 Through the cluster analysis (LISA) that represents the spatial grouping of infant mortality for

176 the years 2010 to 2019 (Figure 6), it can be deduced that during the 10 years of study, the

177 central highlands concentrate the majority of clusters, which are reduced over time, until

178 concentrating in 2019 in the provinces of Carchi, Chimborazo, Cotopaxi, El Oro, Sucumbíos

179 and Morona Santiago. On the contrary, cold spots appear sporadically in Loja, Los Ríos and

180 Morona Santiago.

181 Figure 6. LISA univariate (cluster) maps. 

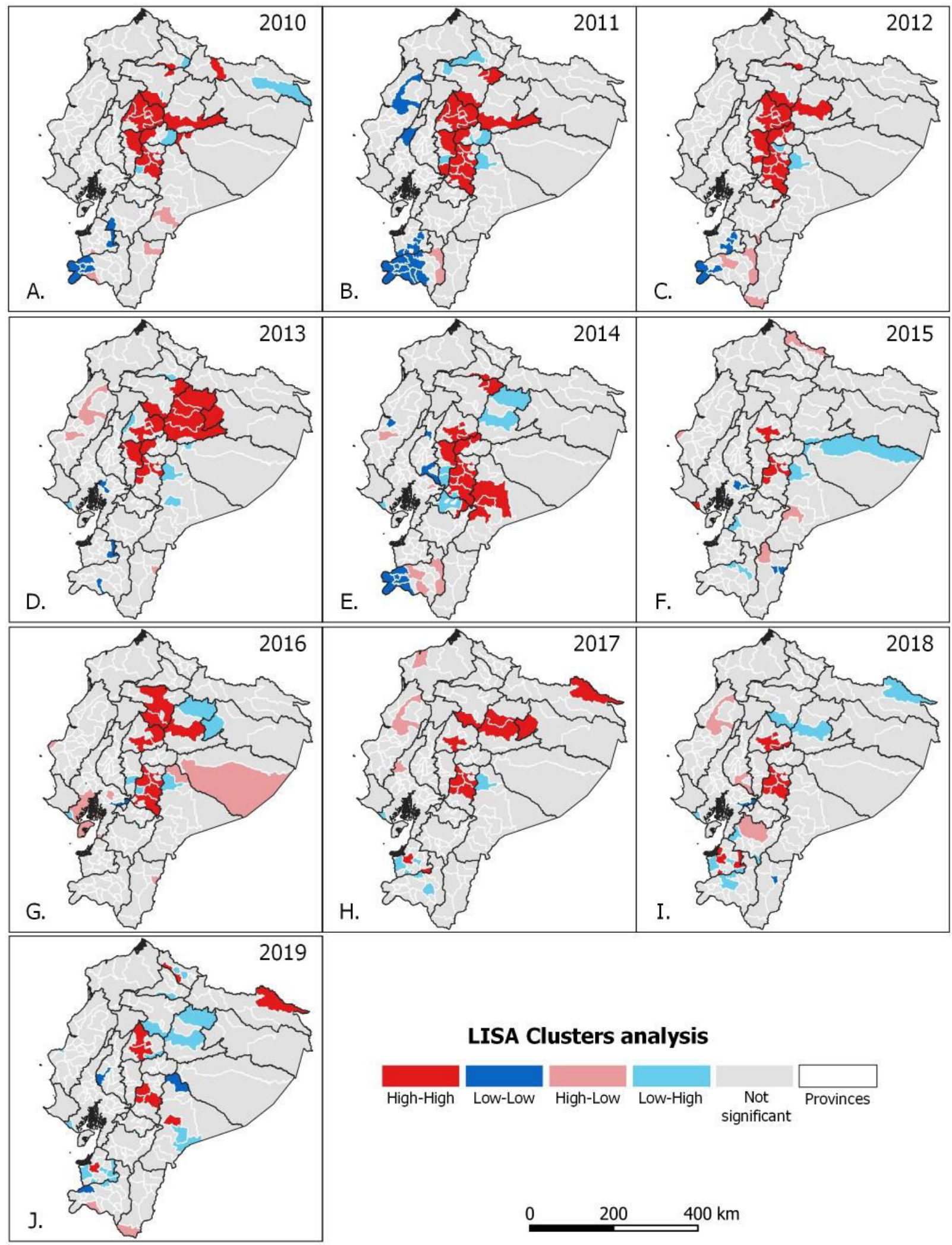

\section{LISA Clusters analysis}

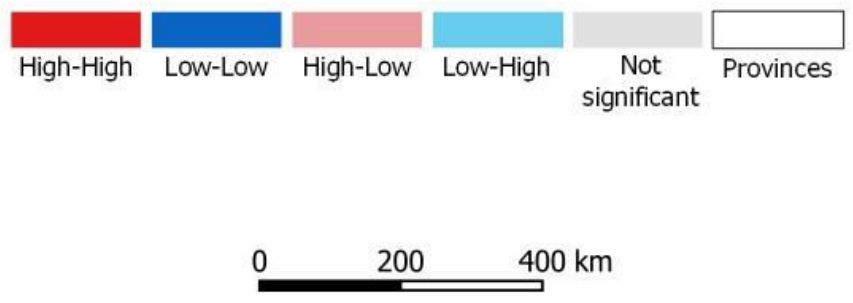

183 By means of the prioritization criteria, eight municipalities were defined, of which four belong

184 to the highlands region, two to the coastal region and two to the Amazon region.

185 Table 1. Municipalities with higher risk of infant mortality. 


\begin{tabular}{llllllll}
\hline Province & Region & Municipality & Infant & IMR & Repeated & Tau & p-value \\
& & & deaths & $\mathbf{2 0 1 9}$ & hotspot & & \\
& & & $\mathbf{2 0 1 9}$ & $(\%)$ & & & \\
Bolívar & Highlands & Guaranda & 29 & 17.86 & 5 & 0.64 & 0.0073 \\
Morona Santiago & Amazon & Morona & 29 & 24.05 & 1 & 0.69 & 0.0123 \\
El Oro & Coastal & Piñas & 68 & 157.77 & 0 & 0.84 & 0.0004 \\
Azuay & Highlands & Cuenca & 179 & 19.44 & 0 & 0.80 & 0.0030 \\
Imbabura & Highlands & Ibarra & 56 & 16.74 & 0 & 0.73 & 0.0024 \\
Carchi & Highlands & Tulcán & 32 & 21.67 & 0 & 0.60 & 0.0318 \\
Guayas & Coastal & Guayaquil & 994 & 21.38 & 0 & 0.56 & 0.0200 \\
Sucumbíos & Amazon & Lago Agrio & 50 & 20.6 & 0 & 0.56 & 0.0491 \\
\hline
\end{tabular}

187 Discussion

188 Eight municipalities were identified as a priority (Table 1), where policies could be 189 implemented to improve the socioeconomic conditions of the population, infrastructure, 190 coverage and accessibility to health services, or even improve the registration of deaths and 191 births, among other strategies that could potentially help reduce the high IMR and reverse the 192 trend. While there are many more municipalities with high IMR, these eight municipalities are 193 of more concern as they have higher IMR values, the trend is increasing over the years, and 194 they generate statistically significant spatial clusters. It is most appropriate that the IMR is 195 reduced over time to the lowest possible levels, yet certain municipalities do not show 196 improvement over the period (increasing and stable trend), which could indicate that more 197 national, provincial or municipal efforts are needed to reduce the IMR.

198 According to the results obtained, the Sierra region has the majority of municipalities with high 199 IMR rates, a growing trend and High-High hotspot values. A study conducted in 1995 in 200 Ecuador showed that the sierra region had the highest rate of the three regions [26], and 201 agreed that the infant mortality profile was mainly due to perinatal conditions (P00-P96), 202 congenital anomalies (Q00-Q99) and respiratory system diseases (J00-J99), which 
203 established the need to improve the quality of Essential Obstetric and Neonatal Care in order

204 to prevent and treat these important health problems in a timely manner [27].

205 Another important point in this study is that the highest infant mortality rates are in the most

206 important urban areas of the country (Quito, Guayaquil and Cuenca) and the trend in these 207 areas is increasing, despite the fact that sanitary conditions and medical assistance are much 208 better than in rural areas; however, it should be taken into account that the information 209 considered was analyzed by municipality of death, so it would also be important to apply it to 210 municipality of residence in order to identify the main focus of risk; secondly, birth and death 211 data should be better recorded in cities than in rural areas, which suggests that there could be 212 an underestimation of the information in areas away from urban centers.

\section{Conclusions}

215 The application of spatial analysis methods in public health, allowed to analyze the temporal 216 and spatial trend of infant mortality rates in continental Ecuador, the findings of this research 217 can provide important inputs for the correct policy intervention [10] in relation to the 218 prioritization of places that require greater accessibility and availability of child health care 219 services, which contribute to the reduction of deaths of children under one year of age.

220 The municipalities with the highest risk of infant mortality should be identified as priorities and 221 benefit from policies and the efficient allocation of resources [13, 14]. Associated with the 222 above, this study provides relevant information for decision makers when planning policies 223 and programs focused on this population sector. The geographic location of hotspots in 224 different regions (amazon, coast, and highlands) and settings (urban or rural) makes it 225 possible to combat health inequalities through the spatial targeting of areas [12], since the 226 social and health characteristics are different for each municipality.

227 Finally, the proposed spatial prioritization method allowed the identification of priority 228 municipalities, specifically those with high rates, increasing temporal trends and significant 229 spatial clusters (Guaranda, Morona, Piñas, Cuenca, Ibarra, Tulcán, Guayaquil and Lago 
230 Agrio), where actions can be taken to prevent and reduce infant mortality. Future studies could

231 focus on determining the social and environmental factors that explain the observed patterns.

\section{Abbreviations}

234 IMR: Infant mortality rate; LISA: Local Indicators of Spatial Association; INEC: National

235 Institute of Statistics and Censuses

236 Declarations

237 Ethics approval and consent to participle: Not applicable

238 Consent for publication: Not applicable

239 Availability of data and materials: Raw data are freely available at (open access):

240 https://www.ecuadorencifras.gob.ec/nacimientos_y_defunciones/

Conflicts of interest. None declared by the authors.

243 Funding: No funding required

244 Contribution of the authors. EQ conceived the original study and reviewed the manuscript; KL

245 and KR collected and processed the data, interpreted the results and wrote the first version of

246 the manuscript; CS and GS supported the application of the LISA method. All authors have

247 read and approved the manuscript and have contributed significantly to the work.

248 Statement. The opinions expressed by the authors are their own and do not necessarily reflect

249 the criteria or policy of the journal.

250 Acknowledgements: Not applicable

References

1. Reidpath DD, Allotey P. Infant mortality rate as an indicator of population health. Journal of Epidemiology \& Community Health. 2003; http://dx.doi.org/10.1136/jech.57.5.344.

2. Dallolio L, Di Gregori V, Lenzi J, et al. Socio-economic factors associated with infant mortality in Italy: an ecological study. Int J Equity Health. 2012; https://doi.org/10.1186/1475-9276-11-45. 
3. Organización Panamericana de la Salud: Lineamientos básicos para el análisis de la mortalidad. https://iris.paho.org/bitstream/handle/10665.2/34492/9789275319819spa.pdf?sequence=7\&isAllowed=y (2017). Accessed 14 Jun 2019.

4. Comisión Económica para América Latina y el Caribe/Fondo de las Naciones Unidas para la Infancia: Mortalidad en la niñez: una base de datos de América Latina desde 1960. https://www.cepal.org/es/publicaciones/1425-mortalidad-la-ninez-base-datosamerica-latina-1960 (2011). Accessed 22 Jul 2019.

5. Organización Panamericana de la Salud: Informe final sobre los Objetivos de Desarrollo del Milenio relacionados con la salud en la Región de las Américas. https://iris.paho.org/bitstream/handle/10665.2/34114/9789275118782_spa.pdf?sequen ce=5\&isAllowed=y (2017). Accessed 14 Jun 2019.

6. Gayawan E, Adarabioyo M, Okewole D, Fashoto S, Ukaegbu J. Geographical variation in infant mortality in West Africa: a geo-additive discrete-time survival modeling. Genus. 2016; https://doi.org/10.1186/s41118-016-0009-8.

7. Huda TM, Hayes A, El Arifeen S, Dibley M. Social determinants of inequalities in child 274 undernutrition in Bangladesh: A decomposition analysis. Maternal \& child nutrition. 2017; https://onlinelibrary.wiley.com/doi/epdf/10.1111/mcn.12440.

8. Instituto Nacional de Estadística y Censos: Nacimientos y defunciones. Ecuador. 2019. https://www.ecuadorencifras.gob.ec/nacimientos_y_defunciones/ Accessed 17 Apr 2019.

9. Organización Panamericana de la Salud/Organización Mundial de la Salud: Indicadores básicos: Situación de salud en las Américas. https://iris.paho.org/bitstream/handle/10665.2/34330/IndBrasicos2017_spa.pdf?seque nce=1\&isAllowed=y (2017). Accessed 22 Jul 2019.

10. Gupta AK, Ladusingh L, Borkotoky K. Spatial clustering and risk factors of infant mortality: district-level assessment of high-focus states in India. Genus. 2016; https://doi.org/10.1186/s41118-016-0008-9. 
11. Almeida MC, Gomes CM, Nascimento LF. Análise espacial da mortalidade neonatal no estado de São Paulo, 2006-2010. Rev Paul Pediatr. 2014; doi:10.1016/j.rpped.2014.01.001.

12. Lome-Hurtado A, Lartigue-Mendoza J, Trujillo J. Modelling local patterns of child mortality risk: a Bayesian Spatio-temporal analysis. BMC Public Health. 2021; https://doi.org/10.1186/s12889-020-10016-9

13. Demirel R, Erdoğan S. Determination of high risk regions of human brucellosis in Turkey using exploratory spatial analysis. Türkiye Klin J Med Sci. 2009;29:25-35.

14. Huda TM, Tahsina T, El Arifeen S, Dibley MJ. The importance of intersectoral factors in promoting equity-oriented universal health coverage: a multilevel analysis of social determinants affecting neonatal infant and under-five mortality in Bangladesh. Glob Health Action. 2016; https://doi.org/10.3402/gha.v9.29741.

15. Ahmed S, Hill K. Maternal mortality estimation at the subnational level: a model-based method with an application to Bangladesh. Bull World Health Organ. 2011;89:12-21.

16. Núñez-González S, Lara-Vinueza AG, Gault C, Delgado-Ron JA. Trends and Spatial Patterns of Suicide Among Adolescent in Ecuador, 1997-2016. Clin Pract Epidemiol Ment Health. 2018; https://doi.org/10.2174/1745017901814010283.

17. Núñez-González S, Delgado-Ron JA, Christopher G, Simancas-Racines D. Trends and Spatial Patterns of Oral Cancer Mortality in Ecuador, 2001-2016. International Journal of Dentistry. 2018; https://doi.org/10.1155/2018/6086595.

18. Núñez-González S, Christopher G, Simancas-Racines Daniel. Spatial analysis of dengue, cysticercosis and Chagas disease mortality in Ecuador, 2011-2016. Tropical Medicine and Hygiene. 2019; https://doi.org/10.1093/trstmh/try106.

19. Sánchez C. Análisis espacial de la transición epidemiológica en la mortalidad infantil en el estado de México. Tesis: Maestría en Análisis Espacial y Geoinformática, Universidad Autónoma del Estado de México. 2019; http://hdl.handle.net/20.500.11799/104843 
313 20. Oti SO, van de Vijver S, Kyobutungi C. Trends in non-communicable disease mortality 314 among adult residents in Nairobi's slums, 2003-2011: applying InterVA-4 to verbal 315 autopsy data. Glob Health Action. 2014; https://doi.org/10.3402/gha.v7.25533.

316 21. Douglas EM, Vogel RM, Kroll CN. Trends in Floods and Low Flows in the United 317 States: Impact of Spatial Correlation. Journal of Hydrology. 2000; $318 \quad$ https://doi.org/10.1016/S0022-1694(00)00336-X.

319 22. Cliff A, Ord K. Spatial Processes, Models and Applications. In: Cho G, editor. 320 Cartography. London: Pion; 1981. p. 59-60.

321 23. Anselin L. Spatial econometrics: methods and models. 1st ed. Springer322 science+Business media, B.V; 1988.

323 24. Waller L, Gotway C. Applied spatial statistics for public health data. 1st ed. Wiley$324 \quad$ Interscience; 2004.

325 25. Anselin L. Local indicators of spatial association-LISA. Geographic Analysis. 1995; $326 \quad$ https://doi.org/10.1111/j.1538-4632.1995.tb00338.x.

327 26. Lozada P, Aguinaga L, Páez R, et al. El peso de la enfermedad en Ecuador. 1995. 328 http://saludecuador.org/maternoinfantil/archivos/A57.PDF Accessed 17 Apr 2019.

329 27. Bustamante K, Armas S. Diagnóstico de salud del Distrito Metropolitano de Quito. 1st ed. Secretaria de salud del DMQ; 2017. 